\title{
Pendant allyl crosslinking as a tunable shape memory actuator for vascular applications
}

\author{
Timothy C. Boire ${ }^{a, 1}$, Mukesh K. Gupta ${ }^{a, 1}$, Angela L. Zachman ${ }^{a}$, Sue Hyun Lee ${ }^{a}$, Daniel A. Balikov ${ }^{a}$, \\ Kwangho Kim ${ }^{\mathrm{b}}$, Leon M. Bellan ${ }^{\mathrm{a}, \mathrm{c}}$, Hak-Joon Sung ${ }^{\mathrm{a}, *}$ \\ ${ }^{a}$ Department of Biomedical Engineering, Vanderbilt University, Nashville, TN 37235, United States \\ ${ }^{\mathrm{b}}$ Institute of Chemical Biology, Vanderbilt University, Nashville, TN 37235, United States \\ ${ }^{\mathrm{c}}$ Department of Mechanical Engineering, Vanderbilt University, Nashville, TN 37235, United States
}

\section{A R T I C L E I N F O}

\section{Article history:}

Received 7 March 2015

Received in revised form 8 May 2015

Accepted 1 June 2015

Available online 10 June 2015

Keywords:

Allylic compounds

Shape memory polymers

Thermally responsive materials

Structure-function relationships

Biocompatibility

\begin{abstract}
A B S T R A C T
Thermo-responsive shape memory polymers (SMPs) can be programmed to fit into small-bore incisions and recover their functional shape upon deployment in the body. This property is of significant interest for developing the next generation of minimally-invasive medical devices. To be used in such applications, SMPs should exhibit adequate mechanical strengths that minimize adverse compliance mismatch-induced host responses (e.g. thrombosis, hyperplasia), be biodegradable, and demonstrate switch-like shape recovery near body temperature with favorable biocompatibility. Combinatorial approaches are essential in optimizing SMP material properties for a particular application. In this study, a new class of thermo-responsive SMPs with pendant, photocrosslinkable allyl groups, $x \% \operatorname{poly}(\varepsilon$-caprolac tone)-co- $y \%(\alpha$-allyl carboxylate $\varepsilon$-caprolactone) ( $x \%$ PCL- $y \%$ ACPCL), are created in a robust, facile manner with readily tunable material properties. Thermomechanical and shape memory properties can be drastically altered through subtle changes in allyl composition. Molecular weight and gel content can also be altered in this combinatorial format to fine-tune material properties. Materials exhibit highly elastic, switch-like shape recovery near $37^{\circ} \mathrm{C}$. Endothelial compatibility is comparable to tissue culture polystyrene (TCPS) and 100\%PCL in vitro and vascular compatibility is demonstrated in vivo in a murine model of hindlimb ischemia, indicating promising suitability for vascular applications.
\end{abstract}

\section{Statement of Significance}

With the ongoing thrust to make surgeries minimally-invasive, it is prudent to develop new biomaterials that are highly compatible and effective in this workflow. Thermo-responsive shape memory polymers (SMPs) have great potential for minimally-invasive applications because SMP medical devices (e.g. stents, grafts) can fit into small-bore minimally-invasive surgical devices and recover their functional shape when deployed in the body. To realize their potential, it is imperative to devise combinatorial approaches that enable optimization of mechanical, SM, and cellular responses for a particular application. In this study, a new class of thermo-responsive SMPs is created in a robust, facile manner with readily tunable material properties. Materials exhibit excellent, switch-like shape recovery near body temperature and promising biocompatibility for minimally-invasive vascular applications.

(c) 2015 Acta Materialia Inc. Published by Elsevier Ltd. All rights reserved.

\section{Introduction}

Shape memory polymers (SMPs) contain chemical and/or physical crosslinks that afford the ability to be programmed and fixed

\footnotetext{
* Corresponding author. Tel.: +1 6153226986 .

E-mail addresses: leon.bellan@vanderbilt.edu (L.M. Bellan), hak-joon.sung@ vanderbilt.edu (H.-J. Sung).

1 Timothy C. Boire and Mukesh K. Gupta contributed equally.
}

into a temporary shape until provoked by a specific external stimulus to recover their original, permanent shape [1]. A diverse array of SMPs have been developed that recover their permanent shape in response to light [2], magnetic fields [3], electricity [4], moisture [5], or $\mathrm{pH}$ [6] for a variety of industrial, aeronautical, and biomedical applications and can be reviewed elsewhere $[1,7,8]$. In contrast to their shape memory alloy counterparts, SMPs can be created with diverse, multi-functional chemistries to enable drastic yet highly-controllable shape responses to various stimuli [9-12]. 
SMPs that are thermo-responsive remain the most convenient and widely studied, drawing extensive interest in the biomedical field in part because of the high predictability and consistency of the body temperature stimulus $[1,13-15]$. The capability of thermo-responsive SMPs to recover their permanent shape near body temperature after programming into a distinct temporary shape provides an opportunity to develop the next generation of minimally-invasive medical devices [1,13-15]. For example, their temporary shape can be programmed to fit into a small-bore incision for catheter insertion at room temperature and, when heated at or near body temperature, the polymeric device recovers its original functional shape, such as a stent mesh for intraluminal expansion [15-17], an expandable foam to fill an aneurysm [1820], a tubular graft to bypass blood flow in the advent of minimally invasive bypass grafting procedures [21], or a corkscrew shape to remove endovascular blood clots [22-24].

To be used in such vascular applications, materials should exhibit mechanical strengths that accomplish intended functions and minimize adverse compliance mismatch-induced host responses [25-28], be biodegradable to prevent infectious complications [29-32], and demonstrate switch-like shape recovery near body temperature [32,33] with favorable biocompatibility [34-36]. SMPs triggered by melting temperature $\left(T_{\mathrm{m}}\right)$ may be more appropriate for many biomedical applications because they tend to exhibit sharper phase transitions and higher, more switch-like shape recovery than SMPs that respond to glass transition temperature $\left(T_{\mathrm{g}}\right)[32,37]$. Moreover, covalently-crosslinked SMP networks are often preferable to physically-crosslinked ones because they tend to undergo less creep and irreversible deformation during programming steps $[1,38]$, exhibiting superior shape memory properties and thermal stability [39]. However, current approaches to synthesize $T_{\mathrm{m}}$-triggered SMP thermosets require an additional methacrylate functionalization step or multistep monomer synthesis $[33,40,41]$.

In this study, a new class of $T_{\mathrm{m}}$-responsive SMPs with pendant, photocrosslinkable allyl groups, $x \%$ poly( $\varepsilon$-caprolactone)-co- $y \%$ ( $\alpha$-allyl carboxylate $\varepsilon$-caprolactone) ( $x \% \mathrm{PCL}-y \% \mathrm{ACPCL})$, are created in a robust, facile manner with readily tunable material properties. While $T_{\mathrm{g}}$-triggered SMPs have been created via thiol-ene crosslinking between monomers containing thiol and allyl groups [42] or via pendant crosslinking of acrylate groups [43], this is the first study to create SMPs by photocrosslinking pendant allyl groups. The $x \% \mathrm{PCL}-y \% \mathrm{ACPCL}$ copolymerization format offers a convenient, combinatorial approach to fine-tune material properties of SMPs. The pendant allyl carboxylate-based crosslinkers enable pendant conjugation to growth factors, therapeutics, and extracellular matrix-derivatives via thiol-ene click chemistry [44,45] or photocrosslinking of modified peptides [46] to control cell and tissue responses. Allyl composition ( $y \%$ ) can be used to simultaneously control both the spacing of netpoints and crystallinity, offering an efficient means to tune thermomechanical, shape memory, and biological functions. Further tweaking of material properties and functions can be attained by altering other physicochemical properties such as molecular weight and gel content. Therefore, the new copolymerization format provides a unique, finely-tunable platform for studying structure-function relationships in order to better control biological responses and meet application requirements [47].

PCL notably has many desirable properties for vascular applications including biocompatibility/bioresorbability, slow biodegradability (2-3 years in vivo), and mechanical compliance [48], but its $T_{\mathrm{m}}\left(>50^{\circ} \mathrm{C}\right)$ is too high for physiological applications. Previous efforts to lower its $T_{\mathrm{m}}$ near $37^{\circ} \mathrm{C}$ and achieve either dual- or triple-shape memory functions involve incorporation or complexation of rigid and/or soft components, blending, branching, and molecular weight alteration $[33,40,41,49-54]$. In this study, the $T_{\mathrm{m}}$ is tuned near body temperature primarily through subtle alteration in the molar composition of $x \%$ PCL- $y$ \%ACPCL. This new pendant-crosslinking system with photocrosslinkable ally-based crosslinkers offers the advantages of facile fabrication, robust tunability of material properties, and further functionalization with bioactive molecules. Molecular weight and gel content can also be controlled in this copolymerization format to fine-tune properties such as mechanical compliance and extensibility to more closely match that of the native artery, in turn reducing thrombotic and restenotic risks $[14,28,48,55]$. These SMPs exhibit exceptional shape memory properties with high elastic recovery and switch-like shape responses near $37^{\circ} \mathrm{C}$. In addition, these SMPs are compatible with vascular endothelial cells (ECs), as indicated by high levels of cell viability ( $\geqslant 85 \%$ after $91 \mathrm{~h}$ relative to tissue culture polystyrene (TCPS)) and healthy cell morphologies. Vascular compatibility (i.e. successful cellularization without inflammatory exacerbation) is also shown in vivo in a murine model of hindlimb ischemia. These material features (e.g. high elastic recovery, ease of manufacturing and programming low cost, vascular compatibility, tunable material properties, mechanical compliance, and biodegradability) are advantageous toward minimally invasive deployment of bulky, complex implantable devices for various biomedical applications [13-15], such as the aforementioned intraluminal stents, bypass grafts, or clot removal devices.

\section{Experimental}

\subsection{Materials}

Lithium diisopropyl amine (LDA), allyl chloroformate, anhydrous tetrahydrofuran (THF), diethylzinc solution (15 wt.\% in toluene), dichloromethane (DCM), ethyl acetate, hexanes, poly(vinyl alcohol) (PVA), and ethanol were used as purchased from Sigma-Aldrich (St. Louis, MO). $\varepsilon$-Caprolactone (CL) was dried with calcium hydride and vacuum distilled. To purify the synthesized $\alpha$-allyl carboxylate $\varepsilon$-caprolactone (ACCL), Silica Gel Premium Rf (Sorbent Technologies, Norcross, GA) was first loaded into a glass column and wetted with $100 \%$ hexanes. Poly(methyl methacrylate) (PMMA) standards (Agilent Technologies, Inc., Santa Clara, CA) were used as purchased. SYLGARD ${ }^{\circledR} 184$ Silicone Elastomer Kit (Dow Corning, Inc., Midland, MI) was used to prepare polydimethylsiloxane (PDMS) molds for preparing SMP shapes. MesoEndo Endothelial Cell Growth Media (Cell Applications, Inc., San Diego, CA) was used as purchased with passage 5-cultured human umbilical vein endothelial cell (HUVEC) and human coronary artery endothelial cell (hCAEC) lines (Cell Applications, Inc., San Diego, CA). Resazurin sodium salt (Sigma-Aldrich) was further diluted from prepared sterile $5 \mathrm{mM}$ stock aliquots. Ethidium Homodimer-1 and Alexa Fluor ${ }^{\circledR} 488$ Phalloidin were used as purchased (Molecular Probes, Eugene, OR). For animal experiments, 5-0 Prolene sutures (Ethicon, Somerville, NJ) and optimal cutting temperature compound (OCT, Sakura Finetek USA, Inc., Torrance, CA) were used as purchased.

\subsection{Synthesis of ACCL monomer}

Analogous to other works [56-58], distilled CL (13.9 mL, $125 \mathrm{mmol}$ ) was added dropwise to a $250 \mathrm{~mL}$ round-bottom flask containing LDA ( $125 \mathrm{~mL}$ of $2 \mathrm{M}$ in THF/n-heptane/ethylbenzene, $250 \mathrm{mmol})$ in anhydrous THF $(200 \mathrm{~mL})$ at $-78{ }^{\circ} \mathrm{C}$. After $1 \mathrm{~h}$, the temperature was raised to $-30^{\circ} \mathrm{C}$ and allyl chloroformate (13.3 $\mathrm{mL}, 125 \mathrm{mmol}$ ) was added dropwise. Thirty minutes later, the temperature was raised to $0{ }^{\circ} \mathrm{C}$ and quenched with saturated $\mathrm{NH}_{4} \mathrm{Cl}(30 \mathrm{~mL})$. The crude ACCL was diluted in $\mathrm{H}_{2} \mathrm{O}(100 \mathrm{~mL})$, extracted with ethyl acetate $(300 \mathrm{~mL} \times 3)$, dried with $\mathrm{Na}_{2} \mathrm{SO}_{4}$, filtered, evaporated, and purified by column chromatography using 
Silica Gel Premium Rf (Sorbent Technologies) with 10\% ethyl acetate in hexanes to yield the novel monomeric compound (58\% yield, $14.3 \mathrm{~g}, 72 \mathrm{mmol}$ ).

\subsection{Synthesis of $x \% P C L-y \% A C P C L$ copolymers}

Analogous to other works [56,59], varying molar ratios of dried ACCL and CL (100 mmol total) were introduced to a pre-dried test tube containing 1,6-hexanediol $(0.5 \mathrm{mmol})$. The polymerization mixture was degassed with two freeze-purge-thaw cycles, submerged in a $140{ }^{\circ} \mathrm{C}$ oil bath, and catalyzed with dropwise addition of $\mathrm{Zn}(\mathrm{Et})_{2}$ (1 mmol, $15 \mathrm{wt}$.\% in toluene) for $1 \mathrm{~h}$. The solution was precipitated in cold diethyl ether and dried under vacuum to yield the novel polymeric compound.

\subsection{Fabrication of crosslinked $x \% P C L-y \% A C P C L$ and $100 \% P C L-$ dimethacrylate SMP films}

Films of uniform thickness $(\sim 0.3 \mathrm{~mm})$ were produced from a DCM solution (10 wt.\% polymer, 1 wt.\% 2,2-dimethoxy-2-phenyla cetophenone) via a thin film applicator (Precision Gage \& Tool, Co., Dayton, $\mathrm{OH})$ and $365 \mathrm{~nm}$ irradiation $\left(4.89 \mathrm{~J} \mathrm{~cm}^{-2}\right.$, $18.1 \mathrm{~mW} \mathrm{~cm}^{-2}, 4 \mathrm{~min}$ ) with a Novacure 2100 Spot Curing System (Exfo Photonic Solutions, Inc., Mississauga, Ontario, Canada). Films were then solvent casted and vacuum dried.

\subsection{Characterization of monomer, polymers, and crosslinked SMP films}

To characterize molar compositions of compounds, ${ }^{1} \mathrm{H}$ NMR was performed on $5 \mathrm{wt}$.\% solutions in $\mathrm{CDCl}_{3}$ with a $300 \mathrm{MHz}$ spectrometer (Bruker Instruments, Inc., Billerica, MA). Molecular weight properties were determined by gel permeation chromatography against PMMA standards using a Phenogel 10E3A column (Phenomenex Inc., Torrance, CA) in THF. Polydispersity (PDI) was determined by the $M_{\mathrm{w}} / M_{\mathrm{n}}$ ratio.

To determine gel content, $X_{\mathrm{G}}$, the dry mass of film samples for each composition, $m_{\text {initial, }}$, was recorded $(n=3-4)$. Following two days of incubation in DCM, samples were extracted, dried, and weighed as $m_{\text {extracted }}$ to calculate $X_{\mathrm{G}}$ :

$X_{\mathrm{G}}=m_{\text {extracted }} / m_{\text {initial }} \times 100 \%$

Thermal properties were determined by subjecting samples ( $n=3-4)$ to two cycles from -80 to $150{ }^{\circ} \mathrm{C}$ on a Q1000 differential scanning calorimeter (DSC) (TA Instruments, Inc., New Castle, DE). $T_{\mathrm{m}}$, crystallization temperature $\left(T_{\mathrm{c}}\right), T_{\mathrm{g}}$, enthalpy of fusion $\left(\Delta H_{\mathrm{m}}\right)$, and enthalpy of crystallization $\left(\Delta H_{\mathrm{c}}\right)$ are reported from the second cycle. \% crystallinity, $X_{\mathrm{C}}$, is calculated as:

$X_{\mathrm{C}}=\Delta H_{\mathrm{m}} / \Delta H_{\mathrm{m}}^{\circ} \times 100 \%$,

where $\Delta H_{\mathrm{m}}^{\circ}=139.5 \mathrm{~J} / \mathrm{g}$, the enthalpy of fusion for $100 \%$ crystalline PCL [60].

To determine mechanical and shape memory properties of the SMP films, rectangular strips $(\sim 8 \mathrm{~mm} \times \sim 2.2 \mathrm{~mm} \times \sim 0.3 \mathrm{~mm})$ were loaded $(n=3-4)$ into a tensile clamp affixed within a dynamic mechanical analyzer (TA Instruments Q2000). Similar to Guo et al. [61], tensile mechanical properties were determined isothermally at $37^{\circ} \mathrm{C}$ with a stress ramp of $0.1 \mathrm{MPa} \mathrm{min}^{-1}$. The modulus at $37^{\circ} \mathrm{C}, E_{\mathrm{tn}}\left(37^{\circ} \mathrm{C}\right)$, was determined by measuring the slope in the initial linear region of the stress vs. strain curve.

Shape memory properties were determined in controlled force mode by stress-controlled thermomechanical cycling in which shape programming is controlled by stress and strain recovery is recorded under stress-free conditions [61-63]. SMP films were (1) heated to $T_{\mathrm{m}}+15^{\circ} \mathrm{C}$, equilibrated for $10 \mathrm{~min}$ to achieve the original permanent shape, $\varepsilon_{\mathrm{p}}(0)$, and programmed into an elongated shape by subjecting to tensile stress $\left(0.004 \mathrm{MPa} \mathrm{min}^{-1}\right.$ to $0.039 \mathrm{MPa})$, (2) cooled $\left(2^{\circ} \mathrm{C} \mathrm{min}^{-1}\right.$ to $\left.0^{\circ} \mathrm{C}\right)$ and equilibrated isothermally for $10 \mathrm{~min}$ at $0^{\circ} \mathrm{C}$ to yield the maximum strain, $\varepsilon_{1}(N)$, and (3) relieved of stress ( $0.004 \mathrm{MPa} \mathrm{min}^{-1}$ to $\left.0 \mathrm{MPa}\right)$ to yield the temporary shape, $\varepsilon_{\mathrm{u}}(N)$. (4) Heating $\left(2{ }^{\circ} \mathrm{C} \mathrm{min}^{-1}\right)$ above $T_{\mathrm{m}}$ yielded the permanent shape, $\varepsilon_{\mathrm{p}}(N)$, after a final $10 \mathrm{~min}$ isothermal equilibration step at $T_{\mathrm{m}}+15^{\circ} \mathrm{C}$. Shape recovery, $R_{\mathrm{r}}(N)$, describes how well shape is recovered $\left(\varepsilon_{\mathrm{p}}(N)\right)$ in comparison to the beginning of the $N$ th cycle $\left(\varepsilon_{\mathrm{p}}(N-1)\right)$ after deforming to maximum strain $\varepsilon_{1}(N)$. Shape fixity, $R_{\mathrm{f}}(N)$, defines the ability to maintain programmed shape $\varepsilon_{1}(N)$ after unloading of stress to yield the temporary shape $\varepsilon_{\mathrm{u}}(N)$.

$R_{\mathrm{r}}(N)=\frac{\varepsilon_{1}(N)-\varepsilon_{\mathrm{p}}(N)}{\varepsilon_{1}(N)-\varepsilon_{\mathrm{p}}(N-1)} \times 100 \% ; \quad R_{\mathrm{f}}(N)=\frac{\varepsilon_{\mathrm{u}}(N)}{\varepsilon_{1}(N)} \times 100 \%$

\subsection{Shape programming}

Closed-end polymer tubes $(\sim 1.0-2.0 \mathrm{~cm}$ length, $\sim 0.90 \mathrm{~mm}$ in I.D., $\sim 1.0-1.6 \mathrm{~mm}$ O.D.) were prepared by dipping a polyvinyl alcohol (PVA)-coated $0.90 \mathrm{~mm}$ O.D. glass capillary in the polymer film preparatory solution and UV-crosslinking as above. Capillaries containing the tubes were dried and immersed in deionized $\mathrm{H}_{2} \mathrm{O}$ and $100 \%$ ethanol before manually pulling the tubes off the capillaries. The tubes were washed with $\mathrm{H}_{2} \mathrm{O}$, dried, and the open side of the tube was closed by dipping it in polymer solution and UV crosslinking. A guitar shape comprised of 96\%PCL-04\%ACPCL was prepared by first laser etching (Epilog Laser, Golden, CO) a $2 \mathrm{~mm}$ PDMS mold containing a CAD-designed guitar, then pouring the 94\%PCL-06\%ACPCL polymer solution into the mold and UV crosslinking $\left(365 \mathrm{~nm}, 26.1 \mathrm{~J} \mathrm{~cm}^{-2}, 290 \mathrm{~mW} \mathrm{~cm}^{-2}\right.$ ) on a $48^{\circ} \mathrm{C}$ hotplate.

\subsection{Analysis of structure-function relationships}

A $13 \times 10$ matrix was constructed containing the mean values of each variable to be compared ( 13 variables) for each of the 10 polymer films. Matrix values were standardized to their $z$-score for more apt comparison between variables, and a covariance matrix was computed and plotted using MATLAB (MathWorks Inc., Natick, MA). To highlight structure-function relationships and minimize redundancy, only a portion of this matrix is presented.

\subsection{HUVEC viability}

To prevent cell attachment on TCPS underneath test films, wells were coated with $1 \%$ agarose solution. Agarose-coated wells were dried, washed with $100 \%$ ethanol, UV sterilized, and washed with MesoEndo Endothelial Cell Growth Media. Ethanol-leached, media-soaked polymer disks $\left(\sim 31 \mathrm{~mm}^{2}, \sim 50 \mu \mathrm{m}\right.$ thick) were then placed on the agarose-coated wells, and Passage 5 HUVECs ( 470 cells $\mathrm{mm}^{-2}$ ) were seeded directly on the film surfaces, TCPS (positive control), and $1 \%$ agarose (negative control) $(n=4)$. After $1.5 \mathrm{~h}, 150 \mu \mathrm{L}$ of media was added. Viability was assessed at 9, 35, and $91 \mathrm{~h}$ time points via the resazurin assay [64]. Briefly, resazurin was added to each well to achieve a $5 \mu \mathrm{M}$ concentration in MesoEndo, incubated for $4 \mathrm{~h}$ at $37^{\circ} \mathrm{C}$, and 560/590 nm excitation/emission of the supernatant was read on an Infinite ${ }^{\circledR}$ M1000 Pro plate reader (Tecan Group Ltd, San Jose, CA). Viable cell number was calculated based on a standard curve of fluorescence intensity from HUVECs on TCPS, and\% cell viability was normalized to TCPS controls. All samples were tested in biological quadruplicates. 


\subsection{HCAEC viability and morphology}

Cell viability was assessed for Passage 5 hCAECs seeded on TCPS (380 cells $\mathrm{mm}^{-2}$ ) and subsequently co-incubated with ethanol-leached, media soaked films $(n=4)$. The resazurin assay was utilized in the same manner as that described above at 24 and $80 \mathrm{~h}$.

Cell morphology was evaluated by seeding the Passage 5 hCAECs directly onto polymer disks $(n=4)$. After 3 days on the polymer disks or TCPS controls, cells were fixed with $4 \%$ paraformaldehyde (15 min), permeabilized with $0.5 \%$ Triton X-100 (10 min), and blocked with $10 \%$ bovine serum albumin (30 min). Cells were then incubated with $2 \mu \mathrm{M}$ Ethidium Homodimer-1 (10 min) and $50 \mu \mathrm{M}$ Alexa Fluor ${ }^{\circledR} 488$ Phalloidin (20 min). Cells on polymer surfaces were imaged on a LSM 510 META Inverted Confocal Microscope (Carl Zeiss, LLC, Thornwood, NY), while TCPS controls were imaged with a Nikon Eclipse Ti inverted fluorescence microscope (Nikon Instruments Inc. Melville, NY). Images were post-processed and analyzed using ImageJ software (NIH, Bethesda, MD).

\subsection{In vivo biocompatibility}

All animal experiments were approved by the Vanderbilt Institutional Animal Care and Use Committee (IACUC) in accordance with the NIH Guide for the Care and Use of Laboratory Animals. Wild type A/J mice were used to develop a model of hindlimb ischemia by ligating the femoral artery and vein at one ligation below the epigastric artery and a second ligation around the artery and vein at a distal location just proximal to the deep femoral branch [65-67]. The femoral artery and vein were then cut between these two sutures. Immediately prior to surgery, closed-end tubular SMP scaffolds (0.9 cm I.D., $1.2 \mathrm{~cm}$ O.D., $1.5 \mathrm{~cm}$ length) comprised of $89 \% \mathrm{PCL}-11 \% \mathrm{ACPCL}$ were rinsed thoroughly with ethanol, UV sterilized, vacuum dried, and implanted into the thigh muscle adjacent to the femoral artery ligations. The surgical incision was then closed with non-degradable sutures. Following the two week implantation, the tubular SMP scaffolds were harvested and embedded in OCT, frozen at $-80^{\circ} \mathrm{C}$ for $24 \mathrm{~h}$, and sectioned ( $5 \mu \mathrm{m}$ sections) using a cryotome. To visualize cell infiltration and inflammatory responses as evidence of in vivo biocompatibility of SMP scaffolds, sections were H\&E stained and imaged on a Nikon Eclipse Ti inverted fluorescence microscope (Nikon Instruments Inc. Melville, NY).

\subsection{Statistical analysis}

All data are reported as mean \pm standard deviation $(n=3-4)$. In comparisons between individual groups, an unpaired, two-tailed Student's $t$-test was used and $p<0.05$ was considered statistically significant.

\section{Results and discussion}

\subsection{Synthesis and characterization of $x \% P C L-y \% A C P C L$ copolymers}

To prepare this new class of SMP library, a novel $\alpha$-allyl carboxylate $\varepsilon$-caprolactone (ACCL) monomer was first synthesized in a single reaction by lithium diisopropyl amine-mediated carbanion formation at the $\alpha$-carbon of $\varepsilon$-caprolactone (CL) and subsequent addition of allyl chloroformate (Fig. 1A) [56,58]. ${ }^{1} \mathrm{H}$ NMR confirmed formation of the desired ACCL product, as indicated by characteristic allyl (5.92 $\left(\boldsymbol{G}_{\boldsymbol{i}}\right), 5.31\left(\boldsymbol{H}_{\boldsymbol{i i}}\right)$ and $4.63\left(\boldsymbol{F}_{\boldsymbol{i i}}\right)$ ppm) and CL peaks (Fig. 1C) $[56,57,59,68]$. Ring-opening (co)polymerization (ROP) of ACCL with $\mathrm{CL}$ using a diethylzinc catalyst and 1,6-hexanediol initiator generated a library of novel $x \%$ PCL- $y \%$ ACPCL ( $x$ and $y$ : molar ratio) copolymers with $y=4.16-14.5 \%$ as determined by the ratio of allylic $\mathrm{CH}$ protons $\left(\boldsymbol{G}_{\boldsymbol{i}}, \delta=5.92 \mathrm{ppm}\right)$ to $\mathrm{CH}_{2}$ protons at the $\varepsilon$-carbon of PCL and ACPCL units $\left(\varepsilon_{i i}, \delta=4.15 \mathrm{ppm}\right)$ (Fig. $1 \mathrm{~B}$ and D, Table 1) [56,57,59,68]. As a control, 100\%PCL (10.1016/j.actbio.2015.05.027, $\left.M_{\mathrm{n}}=11300 \mathrm{Da}, \quad \mathrm{PDI}=1.54\right)$ was similarly synthesized by ROP of CL using stannous octoate and terminally-functionalized via reaction with 2-isocyanatoethyl methacrylate to yield 100\%PCL-dimethacrylate (100\%PCL-DMA, Table $1, M_{\mathrm{n}}=11628 \mathrm{Da}$, $\mathrm{PDI}=1.41)$ with a terminal hydroxyl-to-methacrylate conversion $\left(D_{\mathrm{M}}\right)$ of $90.5 \%$ (Fig. S1, Eq. S1) [38,69]. Allylic compositions attained were lower than the ACCL:CL feed ratios due to lower reactivity of the ACCL monomer (Table 1 and Fig. 1E) [56,59]. Molecular weight (Table $1, M_{\mathrm{n}}=12-19 \mathrm{kDa}$, polydispersity index $(\mathrm{PDI})=1.78-2.50$ ] was controlled by the 1,6-hexanediol initiator: total monomer ratio but was also influenced by the feed ratio of the less reactive ACCL monomer [56,59]. The higher PDIs and lower yields (22.6-56.6\%) attained for these copolymers may be due to transesterification reactions involving both the polyester backbone and pendant allyl carboxylates $[41,56,59]$. There is a clear inverse relationship between several thermal properties and allyl composition, as the amorphous ACPCL disrupts PCL crystallinity, lowering the $T_{\mathrm{m}}$ and $\%$ crystallinity $\left(X_{C}\right)$ (Table 1$)$.

\subsection{Fabrication and characterization of crosslinked $x \% P C L-y \% A C P C L$ SMP networks}

A subset of $x \%$ PCL- $y \% A C P C L$ copolymers and the 100\%PCL-DMA control were photocrosslinked to create the shape memory effect and evaluated in terms of gel content, thermal, mechanical, and shape memory properties. It was desired to produce SMPs with $T_{\mathrm{m}}$ 's both slightly above and below $37^{\circ} \mathrm{C}$ as surgical preferences for the onset of shape recovery depend on the particular application $[15,70,17]$. In order to be used for various vascular applications (e.g. endovascular stents, bypass grafts), it was also desired that the SMP library exhibits tunable mechanical properties, with sufficient compliance and extensibility. Moreover, complete and repeatable shape recovery with an on-off "switch-like" response to small temperature changes is sought after in order to tightly control shape memory behavior and preserve implant integrity and function following shape programming and recovery.

Gel content, which relates to the \% crosslinking of the material, is independent of composition (Fig. 5, subset) and was an average of $57.3 \pm 7.2 \%$ for the $x \%$ PCL- $y \%$ ACPCL films after photocrosslinking $\left(365 \mathrm{~nm}, 4.89 \mathrm{~J} \mathrm{~cm}^{-2}, 18.1 \mathrm{~mW} \mathrm{~cm}^{-2}\right)$, well above the $10 \%$ [71] or $30 \%$ [72] threshold for achieving the shape memory effect in other SMP networks (Table 2). Higher gel content films can be achieved for each composition by increasing the UV dosage, but are not included here because they exhibit hindered shape memory functions due to low crystallinity. Crosslinking of the materials resulted in a $T_{\mathrm{m}}$ reduction from $45.9-32.5^{\circ} \mathrm{C}$ to $43.4-29.7^{\circ} \mathrm{C}$ for $y=4.16-$ $14.5 \%$ copolymer films (Tables 1 and 2 ) due to the restricted mobility of the crosslinked polymer chains $[33,41,61]$. This reduced chain mobility also disrupts the alignment of chains after melting, as indicated by a reduction in the \% crystallinity $\left(X_{C}\right)$ after crosslinking [41]. There is a clear dependence of all thermal properties (except for $T_{\mathrm{g}}$ ) on molar composition for the crosslinked polymers (Table 2, Figs. 2 and 5), as amorphous ACPCL disrupts the crystallinity of PCL and simultaneously lowers the $T_{\mathrm{m}}, X_{\mathrm{C}}$, crystallization temperature $\left(T_{\mathrm{c}}\right)$, and enthalpy of crystallization $\left(\Delta H_{\mathrm{c}}\right)$. Copolymers with $>15 \%$ ACPCL follow the same trend, but were not considered for this paper because their low crystallinity inhibits their shape memory utility. The $X_{\mathrm{C}}$ generated is similar to branched PCL crosslinked films [33], indicating that switch-like shape recovery behavior is feasible with these SMPs. Crosslinking produced a library of SMPs with ideal switching temperatures (i.e. $T_{\mathrm{m}}$ 's near $37^{\circ} \mathrm{C}$ ) and sufficient $X_{\mathrm{C}}$ for 
A

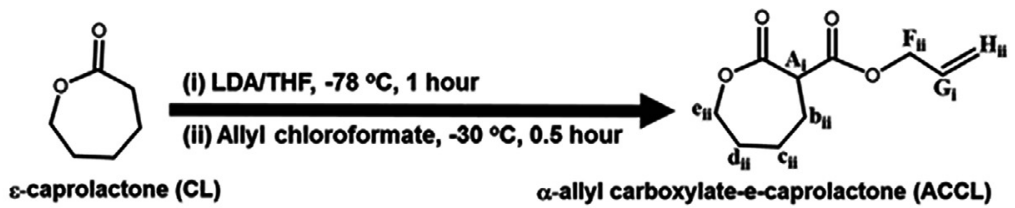

B<smiles>OCCCCCCO</smiles><smiles>O=C1CCCCC1</smiles>

CL

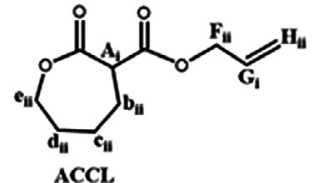

$\mathrm{Zn}(\mathrm{Et})_{2,}, 140^{\circ} \mathrm{C}, 1$ hour

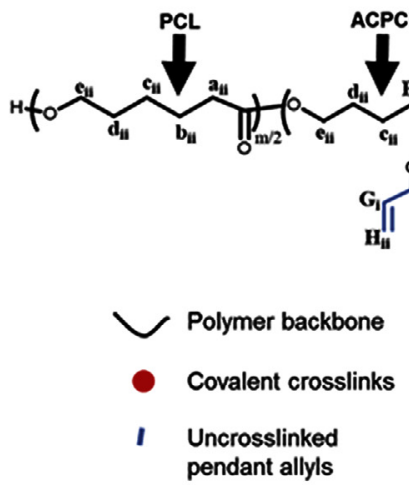
pendant allyls

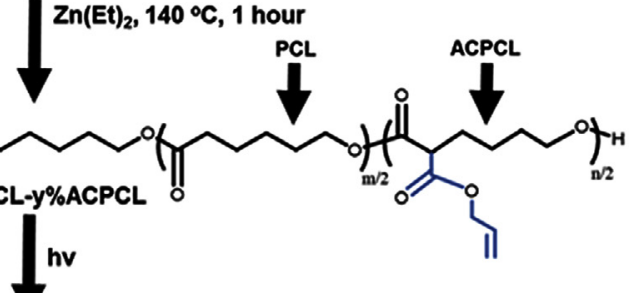
hv
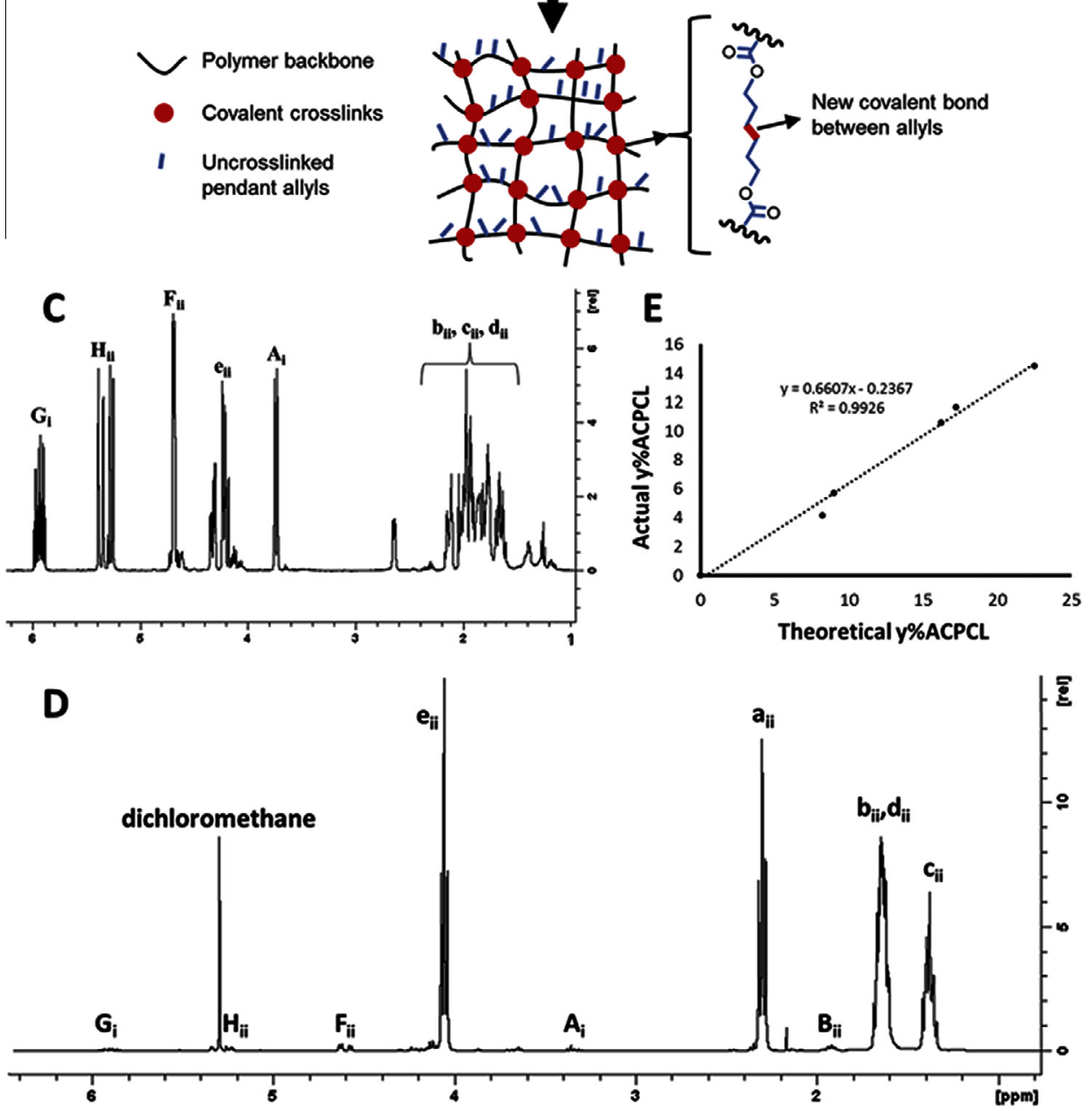

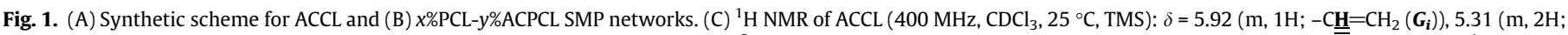

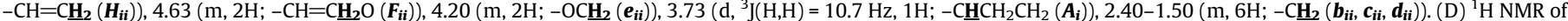

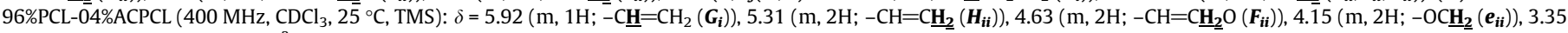

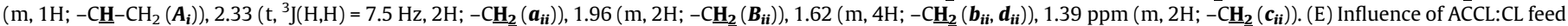
ratio on $x \%$ PCL- $y \%$ ACPCL molar composition.

complete shape recovery and switch-like behavior in physiological applications.

Mechanical properties of the SMP test films were assessed isothermally at $37{ }^{\circ} \mathrm{C}$ to determine suitability for vascular applications. The elasticity was of the same order of magnitude or one lower than the 100\%PCL-DMA control (Table 3, for $y=4.16$ 14.5\%: tensile modulus at $\left.37^{\circ} \mathrm{C}\left(E_{\text {tn }}\left(37^{\circ} \mathrm{C}\right)\right)=70.8-2.48 \mathrm{MPa}\right)$, which may be considered desirable compliance for vascular 
Table 1

Characterization of $x \% \mathrm{PCL}-y \% \mathrm{ACPCL}$ copolymers.

\begin{tabular}{|c|c|c|c|c|c|c|c|c|c|}
\hline Copolymer & Theoretical $y(\%)$ & Actual $y(\%)$ & Yield (\%) & Initiator:monomer & $M_{\mathrm{n}}(\mathrm{Da})$ & $M_{\mathrm{w}}(\mathrm{Da})$ & PDI & $T_{\mathrm{m}}\left({ }^{\circ} \mathrm{C}\right)$ & $X_{\mathrm{C}}(\%)$ \\
\hline $100 \% \mathrm{PCL}$ & 0.00 & 0.00 & 86.2 & $1: 100$ & 11300 & 17368 & 1.54 & $53.0 \pm 0.2$ & $56.6 \pm 1.5$ \\
\hline 100\%PCL-DMA & 0.00 & 0.00 & $\mathrm{~N} / \mathrm{A}$ & $\mathrm{N} / \mathrm{A}$ & 11628 & 16417 & 1.41 & $50.7 \pm 0.5$ & $45.8 \pm 1.9$ \\
\hline 96\%PCL-04\%ACPCL & 8.24 & 4.16 & 44.8 & $1: 200$ & 15060 & 26870 & 1.78 & $45.9 \pm 0.3$ & $41.6 \pm 1.2$ \\
\hline 94\%PCL-06\%ACPCL & 9.03 & 5.74 & 38.3 & $1: 200$ & 16546 & 39050 & 2.36 & $47.1 \pm 0.1$ & $36.1 \pm 0.5$ \\
\hline 89\%PCL-11\%ACPCL & 16.2 & 10.6 & 39.8 & $1: 200$ & 13627 & 34049 & 2.50 & $39.1 \pm 0.3$ & $30.4 \pm 0.7$ \\
\hline 88\%PCL-12\%ACPCL & 17.2 & 11.7 & 22.6 & $1: 315$ & 19087 & 36430 & 1.91 & $41.6 \pm 0.2$ & $31.1 \pm 0.7$ \\
\hline 85\%PCL-15\%ACPCL & 22.5 & 14.5 & 56.6 & $1: 200$ & 12095 & 28931 & 2.39 & $32.5 \pm 0.4$ & $24.4 \pm 0.9$ \\
\hline
\end{tabular}
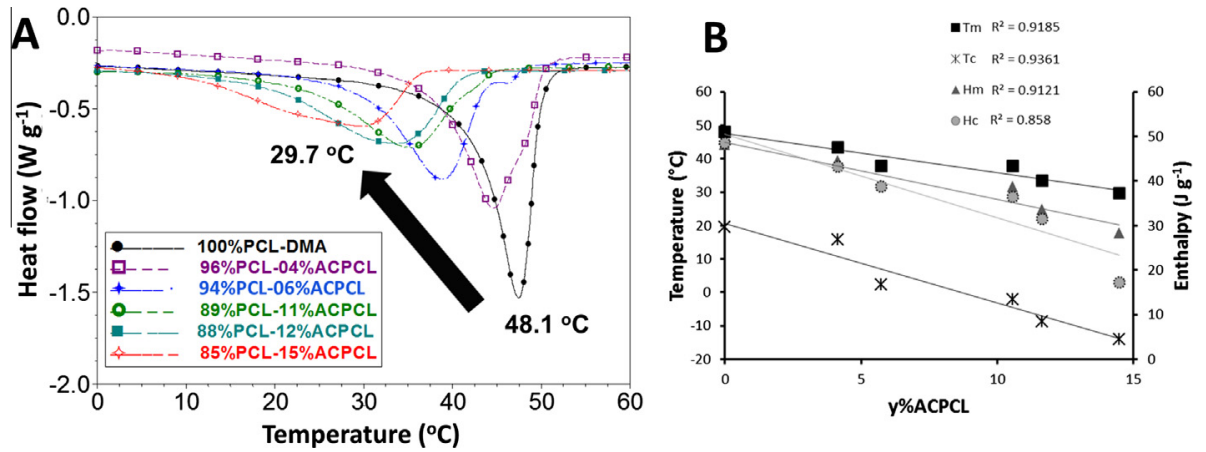

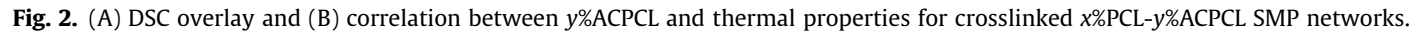

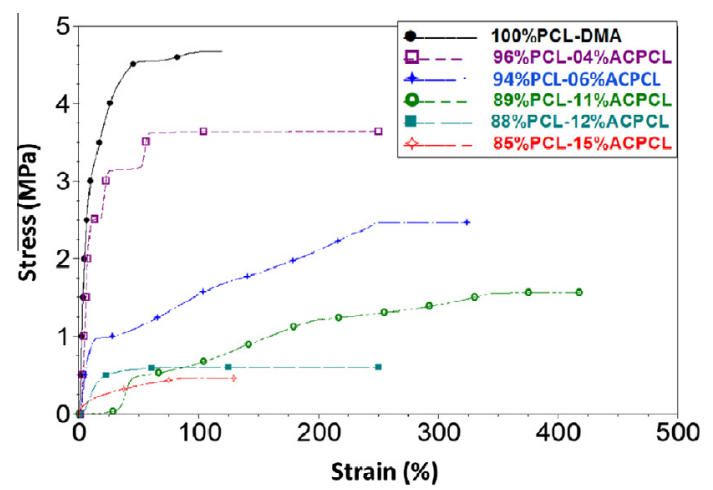

Fig. 3. Stress vs. strain curves for crosslinked $x \%$ PCL-y\%ACPCL SMP networks at $37^{\circ} \mathrm{C}$.

applications considering that this is only marginally less compliant than arteries $[14,28,33,48,55]$. By comparison, healthy human coronary arteries exhibit an average physiological elastic modulus of $1.48 \mathrm{MPa}$ [73]. The higher $y$ \%ACPCL crosslinked copolymer films displayed an order of magnitude lower $E_{\mathrm{tn}}\left(37^{\circ} \mathrm{C}\right)$ that more closely matches that of native arteries and is primarily the result of these materials partially or fully melting at $37^{\circ} \mathrm{C}$ [33]. Stress-to-break, $\sigma_{\text {max }}$, exhibits a similar trend as $X_{\mathrm{C}}$, decreasing from 3.15 to $0.46 \mathrm{MPa}$ as $y \%$ increased from $4.16 \%$ to $14.5 \%$. All materials exhibit good ductility at $37{ }^{\circ} \mathrm{C}$, with $>100 \%$ strain-to-break, $\varepsilon_{\max }$, for every test film but $85 \%$ PCL-15\%ACPCL $\left(\varepsilon_{\max }=71.5 \pm 40.6 \%\right.$ ), which may be adversely affected by its low crystallinity (Table 3 ). These experiments demonstrate that the library of crosslinked SMPs has appropriate extensibility and compliance for vascular applications.

Next, their shape memory properties were evaluated by stress-controlled thermomechanical cycling in which shape programming is controlled by stress and strain recovery is recorded under stress-free conditions (Fig. 4A-C) [61-63]. Some of the SMP films, most notably 96\%PCL-04\%ACPCL, exhibit shape changes when heated above their $T_{\mathrm{m}}$ for the first time during the equilibration step at $T_{\mathrm{m}}+\sim 15^{\circ} \mathrm{C}$ before any stress is applied (i.e. $\sim 39 \%$ negative strain at $60^{\circ} \mathrm{C}$ in Fig. 4A). Similar to crosslinked semi-crystalline SMPs utilized in heat-shrink tubing applications [1,74-76], this indicates that the film fabrication process (i.e. UV irradiating the SMPs below their $T_{\mathrm{m}}$ ) can effectively fix the films in an ambient temporary shape. Heating beyond their $T_{\mathrm{m}}$ for the first time triggers recovery of an entropically-favored permanent shape, $\varepsilon_{\mathrm{p}}(0)$, that may differ from the temporary shape formed during the crosslinking event at room temperature. SMPs should therefore be photocrosslinked above their $T_{\mathrm{m}}$ in the future to avoid any possible unanticipated alterations in the permanent shape. Smaller stresses than those in Fig. 3 are required to achieve comparable levels of strain because the programming step is carried out at temperatures higher than $37^{\circ} \mathrm{C}$ $\left(T_{\mathrm{m}}+\sim 15^{\circ} \mathrm{C}\right)$. Shape fixity $\left(R_{\mathrm{f}}\right)$ represents the ability of materials to be programmed and fixed into a temporary shape (e.g. thread-like shape) and was $>98 \%$ for select films of every composition (Table 3). This indicates that even less crystalline materials have strong enough interactions between polymer chains [1], at least at freezing temperatures, to properly immobilize and fix a temporary shape. Shape recovery after the first cycle, $R_{\mathrm{r}}(N)$, which indicates the quantitative ability of materials to recover their permanent shape (e.g. tubular shape), was $>98 \%$ for test films of every composition except for 85\%PCL-15\%ACPCL $\left(R_{\mathrm{r}}(N)=86.9 \pm 4.7 \%\right)$ (Table 3 ). The lower $R_{\mathrm{r}}, X_{\mathrm{C}}$, and ductility of crosslinked 85\%PCL-15\%ACPCL films indicate that the lower crystallinity and energy associated with the melting transition of materials with $\geqslant 15 \%$ ACPCL hinders their shape memory utility. The highly repeatable nature of shape programming and recovery for these SMPs with $<15 \% A C P C L$ is illustrated in three consecutive thermomechanical cycles with 96\%PCL-04\%ACPCL and 89\%PCL-11\%ACPCL along with the $100 \%$ PCL-DMA control (Fig. 4A-C). This indicates their promising utility in biomedical applications involving deployment and recovery from minimally-invasive surgical devices such as catheters or laparoscopes [1,13-15]. Shape memory demonstrations further affirm this potential capability to be programmed into and recover complex shapes in biomedical applications (Fig. 4D-L, Video S1), including a thread-to-tube transition for possible minimally-invasive catheter/laparoscope deployment in 

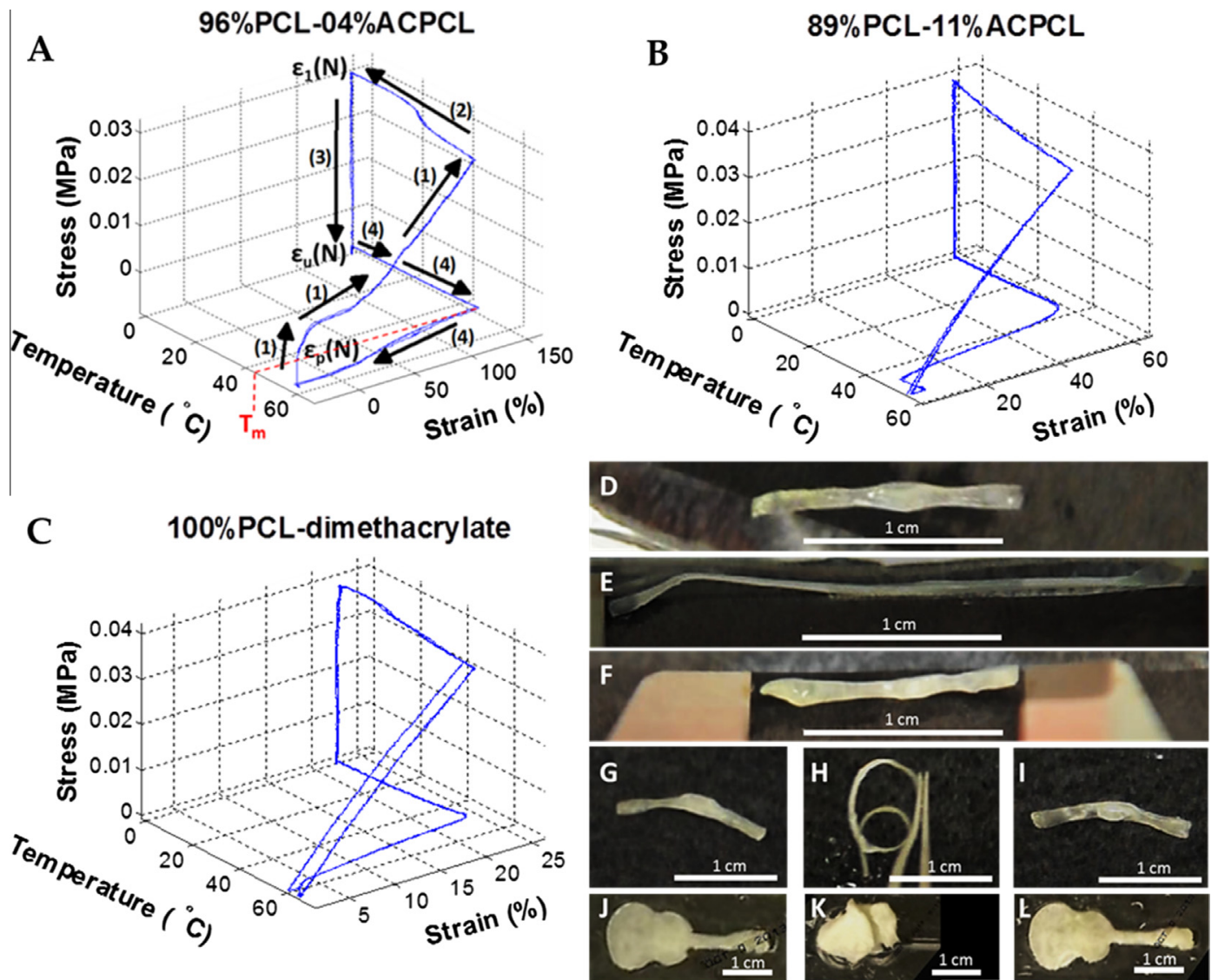

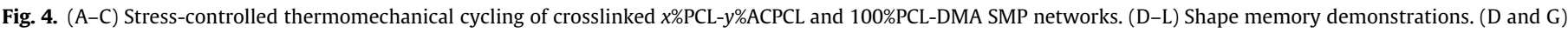

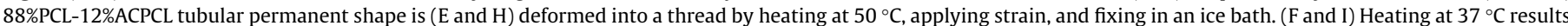

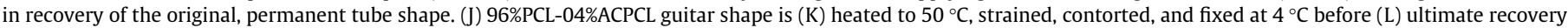
of the complex guitar shape at $48^{\circ} \mathrm{C}$.
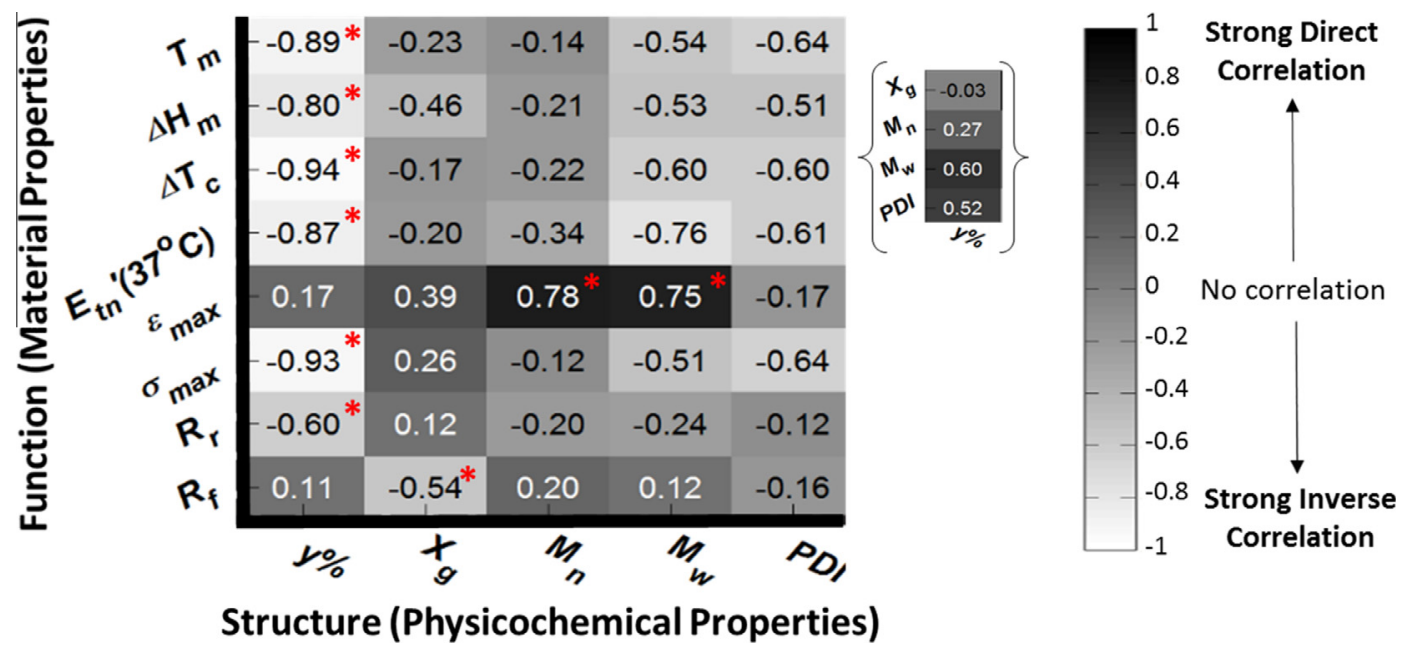

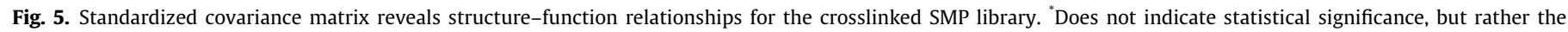

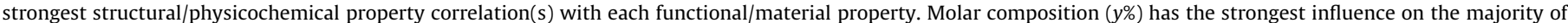

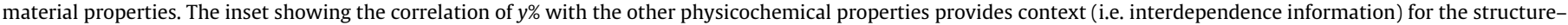
function relationships generated from the SMP library.

endovascular stenting, bypass grafting, or clot removal at $37^{\circ} \mathrm{C}$. Shape recovery occurs rapidly (within seconds) and fully once the SMPs are exposed to a temperature at or beyond their midpoint $T_{\mathrm{m}}$ (Video S1). All copolymers, especially those with <15\% ACPCL, possess exceptional, tightly-controllable shape memory capabilities.

\subsection{Elucidation of structure-function relationships}

To better elucidate correlations of material properties $\left(T_{\mathrm{m}}, \Delta H_{\mathrm{m}}\right.$, $\left.T_{\mathrm{c}}, E_{\mathrm{tn}}\left(37^{\circ} \mathrm{C}\right), \sigma_{\max }, \varepsilon_{\max }, R_{\mathrm{r}}(N), R_{\mathrm{f}}(N)\right)$ with physicochemical properties ( $y \%$ ACPCL, $M_{\mathrm{n}}, M_{\mathrm{w}}, \mathrm{PDI}, X_{\mathrm{G}}$ ), a standardized covariance matrix was constructed from mean property values of an expanded 
Table 2

Gel content and thermal properties of crosslinked $x \%$ PCL- $y \%$ ACPCL SMP films.

\begin{tabular}{|c|c|c|c|c|c|c|c|}
\hline Composition & $X_{\mathrm{G}}(\%)$ & $T_{\mathrm{m}}\left({ }^{\circ} \mathrm{C}\right)$ & $\Delta H_{\mathrm{m}}\left(\mathrm{J} \mathrm{g}^{-1}\right)$ & $X_{\mathrm{C}}(\%)$ & $T_{\mathrm{c}}\left({ }^{\circ} \mathrm{C}\right)$ & $\Delta H_{\mathrm{c}}\left(\mathrm{J} \mathrm{g}^{-1}\right)$ & $T_{\mathrm{g}}\left({ }^{\circ} \mathrm{C}\right)$ \\
\hline 100\%PCL-DMA & $72.0 \pm 17$ & $48.1 \pm 0.4$ & $48.2 \pm 0.5$ & $34.6 \pm 0.4$ & $19.5 \pm 1.0$ & $48.6 \pm 0.38$ & $-54.2 \pm 3.0$ \\
\hline 96\%PCL-04\%ACPCL & $63.0 \pm 8.6$ & $43.4 \pm 1.2$ & $44.6 \pm 3.2$ & $32.0 \pm 2.3$ & $15.8 \pm 0.89$ & $43.2 \pm 6.1$ & $-56.9 \pm 0.10$ \\
\hline 94\%PCL-06\%ACPCL & $60.3 \pm 21$ & $37.9 \pm 0.9$ & $39.1 \pm 5.3$ & $28.0 \pm 3.8$ & $2.44 \pm 0.54$ & $38.7 \pm 4.8$ & $-58.8 \pm 4.9$ \\
\hline 89\%PCL-11\%ACPCL & $49.0 \pm 6.2$ & $37.9 \pm 0.7$ & $38.7 \pm 1.6$ & $27.7 \pm 1.2$ & $-2.10 \pm 0.74$ & $36.5 \pm 0.82$ & $-57.1 \pm 1.5$ \\
\hline 88\%PCL-12\%ACPCL & $64.1 \pm 3.1$ & $33.4 \pm 1.2$ & $33.7 \pm 1.1$ & $24.2 \pm 0.8$ & $-8.73 \pm 0.20$ & $31.4 \pm 2.2$ & $-58.7 \pm 2.2$ \\
\hline 85\%PCL-15\%ACPCL & $50.3 \pm 0.64$ & $29.7 \pm 0.2$ & $28.3 \pm 2.7$ & $20.3 \pm 1.9$ & $-13.9 \pm 0.84$ & $17.2 \pm 0.87$ & $-57.5 \pm 1.1$ \\
\hline
\end{tabular}

Table 3

Mechanical and shape memory properties of crosslinked SMP films.

\begin{tabular}{|c|c|c|c|c|c|c|}
\hline Composition & $E_{\text {tn }}\left(37^{\circ} \mathrm{C}\right)(\mathrm{MPa})$ & $\varepsilon_{\max }(\%)$ & $\sigma_{\max }(\mathrm{MPa})$ & $R_{\mathrm{r}}(1)(\%)$ & $R_{\mathrm{r}}(N)(\%)$ & $R_{\mathrm{f}}(N)(\%)$ \\
\hline 100\%PCL-DMA & $66.7 \pm 41.6$ & $90.2 \pm 110$ & $3.86 \pm 2.2$ & $99.7 \pm 0.12$ & $99.5 \pm 1.4$ & $98.3 \pm 1.5$ \\
\hline 96\%PCL-04\%ACPCL & $70.8 \pm 37.4$ & $126 \pm 115$ & $3.15 \pm 0.39$ & $99.2 \pm 0.81^{\mathrm{a}}$ & $99.4 \pm 1.3^{\mathrm{a}}$ & $94.2 \pm 1.2^{\mathrm{a}}$ \\
\hline 94\%PCL-06\%ACPCL & $3.05 \pm 2.64$ & $253 \pm 19.4$ & $2.36 \pm 0.87$ & $93.7 \pm 0.87$ & $98.5 \pm 0.57$ & $98.7 \pm 0.27$ \\
\hline 89\%PCL-11\%ACPCL & $5.44 \pm 1.10$ & $300 \pm 127$ & $1.43 \pm 0.31$ & $97.7 \pm 0.62$ & $99.7 \pm 0.74$ & $99.8 \pm 0.16$ \\
\hline 88\%PCL-12\%ACPCL & $3.64 \pm 1.10$ & $109 \pm 110$ & $1.14 \pm 0.59$ & $99.3 \pm 9.9$ & $99.0 \pm 6.2$ & $98.6 \pm 0.75$ \\
\hline 85\%PCL-15\%ACPCL & $2.48 \pm 1.11$ & $71.5 \pm 40.6$ & $0.463 \pm 0.4$ & $60.1 \pm 0.64$ & $86.9 \pm 4.7$ & $99.6 \pm 0.23$ \\
\hline
\end{tabular}

a A 96\%PCL-04\%ACPCL test film with $X_{\mathrm{G}}=36.7 \pm 8.6 \%$ had $R_{\mathrm{r}}(1)=99.9 \pm 0.2, R_{\mathrm{r}}(N)=99.8 \pm 0.4 \%$, and $R_{\mathrm{f}}(N)=99.8 \pm 0.1 \%$.

polymer library (Fig. 5). Covariances (covs) closest to the absolute value of 1 indicate the strongest correlations between variables, with positive and negative values indicating direct and inverse relations, respectively. While it should be cautioned that the low number of polymer test groups $(n=10)$, inherent variance in data, interdependent relationships, and experimental parameters used to derive mechanical and shape memory properties (e.g. stress or strain rate, fixation and deformation temperature) can skew these correlations, some basic and useful conclusions can be drawn from this analysis. Thermal properties $\left(T_{\mathrm{m}}, \Delta H_{\mathrm{m}}, T_{\mathrm{c}}, \Delta H_{\mathrm{c}}\right), E_{\mathrm{tn}}\left(37^{\circ} \mathrm{C}\right)$, and $\sigma_{\max }$ correlate most strongly with $y$ \% ACPCL $(\operatorname{cov}=-0.80$ to -0.94$)$, indicating the dominant role of molar composition in modulating thermal properties. The effect of molar composition on many material properties can be explained by the fact that altering allyl content simultaneously changes both the crystallinity and spacing of netpoints of the crosslinked networks. $R_{\mathrm{r}}(N)$ was also most impacted by molar composition ( $\operatorname{cov}=-0.60$ ), although it is conceivable that programming parameters (e.g. fixation and deformation temperature, stress or strain rate) could be adjusted to improve $R_{\mathrm{r}}(N)$ for higher $y$ \%ACPCL copolymers [77-79]. Also of note, $M_{\mathrm{n}}$ only correlates strongly with $\varepsilon_{\max }(\operatorname{cov}=0.78)$, indicating that increasing $M_{\mathrm{n}}$ may be able to improve the extensibility of these SMPs if that is deemed a rate-limiting factor in implant performance. Along the same lines, it may be possible to increase $R_{\mathrm{f}}(N)(\operatorname{cov}=-0.54)$ and $\Delta H_{\mathrm{m}}(\operatorname{cov}=-0.46)$ by adjusting $X_{\mathrm{G}}$. While a low number of polymer test groups, variability in the data, interdependencies, and the potential influence of experimental parameters convolute this analysis, it appears that the majority of material properties are most affected by molar composition. Furthermore, it appears that many material properties can be tweaked via modulation of other physicochemical properties to comprise PCL-ACPCL SMPs with optimal thermal, mechanical, and shape memory properties for a particular application. Firmer conclusions can be derived from these correlations if the polymer library is further expanded, thereby minimizing variance in the data and interdependent effects.

\subsection{Cell viability studies}

To assess biocompatibility of the films in vitro, HUVECs were seeded on washed polymer films and their viability was measured and normalized to TCPS over the course of four days using the resazurin assay (Fig. 6A) [64]. The 85\%PCL-15\%ACPCL copolymer was not considered for this test due to its lower ductility and shape memory utility. $100 \%$ PCL (Sigma-Aldrich, $M_{\mathrm{n}}=70-90 \mathrm{kDa}$ ) is an appropriate control film as the base polymer of $x \% \mathrm{PCL}-y \% \mathrm{ACPCL}$
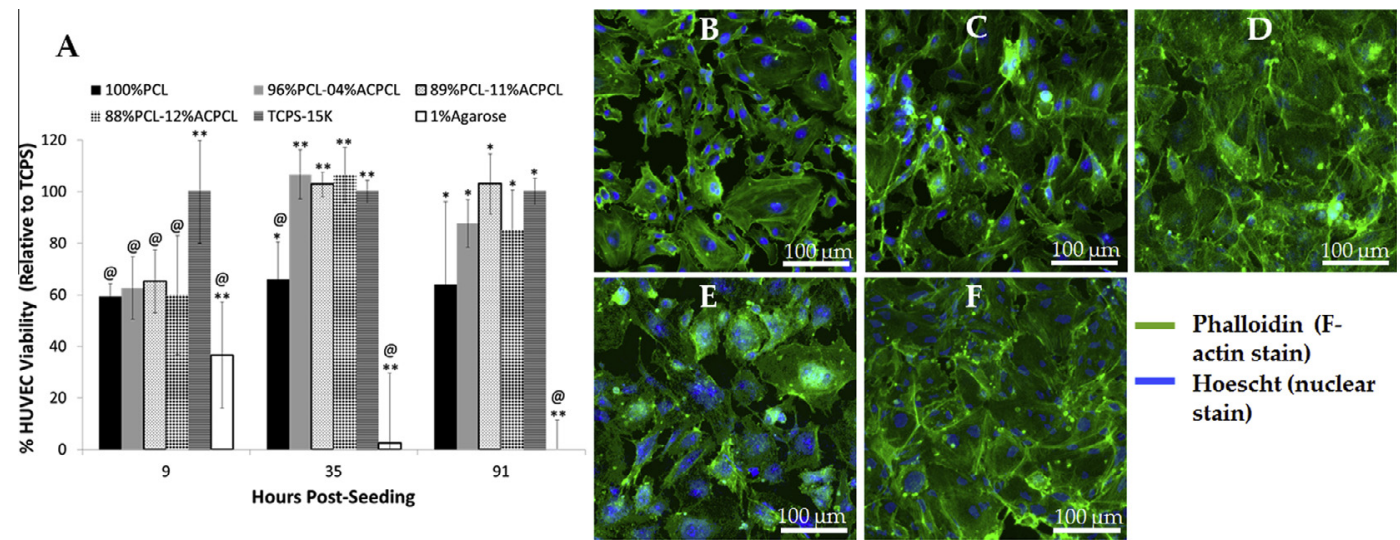

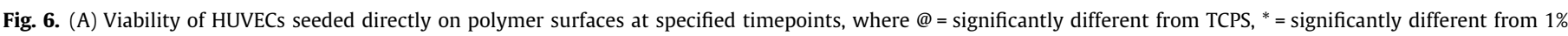

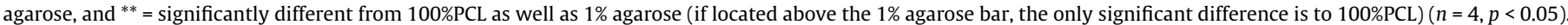

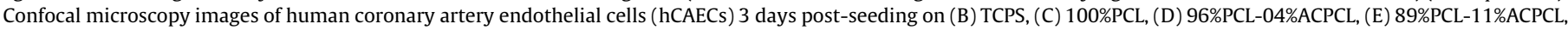
and (F) 88\%PCL-12\%ACPCL exhibit trademark cobblestone morphology (Green: F-actin, Blue: Nuclei). 


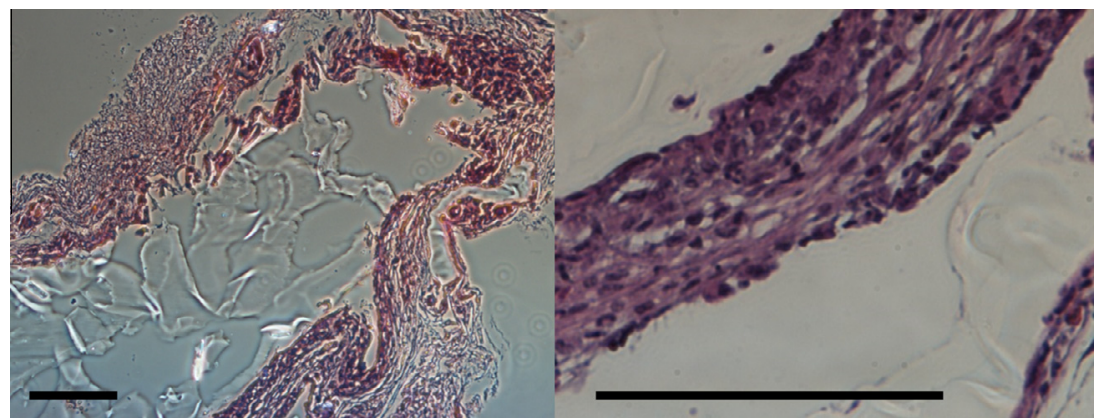

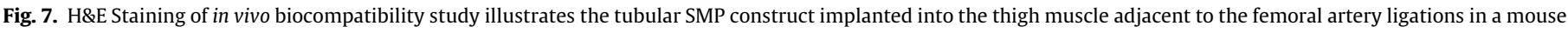
model of hindlimb ischemia. Left $(10 \times)$ and right $(40 \times)$; Scale bar $=100 \mathrm{~m}$.

films and is well known to be biocompatible $[35,80]$. Nine hours post-seeding, there was no statistically significant difference in HUVEC viability on test SMP films (60.0-65.2\% relative to TCPS) compared to $100 \% \mathrm{PCL}(59.4 \pm 4.9 \%)$, affirming that cell seeding was equivalent across the films. At later timepoints, HUVEC viability on all copolymer films (102.9-106.7\% for $35 \mathrm{~h}$ and $85.0-103.0 \%$ for $91 \mathrm{~h}$ ) was comparable to that on the TCPS control (100\%) and greater than that on $100 \% \mathrm{PCL}(66.0 \pm 14.4 \%$ and $64.1 \pm 32.0 \%$, respectively). hCAECs seeded on TCPS and immediately co-incubated with polymer films exhibited a viability of $>79 \%$ at $24 \mathrm{~h}$ and $>85 \%$ at $80 \mathrm{~h}$ relative to TCPS, with no statistically significant differences observed between test substrates $(n=4)$ (Fig. S2). In a separate experiment, hCAECs seeded directly on films demonstrate a trademark cobblestone morphology indicative of their excellent viability on all films three days post-seeding (Fig. 6B-F) [81]. These experiments therefore demonstrate that the SMPs are compatible with vascular ECs.

\subsection{In vivo biocompatibility}

The biocompatibility of SMPs was further assessed in vivo in terms of cellular infiltration and host inflammatory responses elicited by SMP implantation in a mouse model of hindlimb ischemia. A washed, sterilized tubular SMP scaffold was implanted into the thigh muscle adjacent to the two femoral artery ligations. The 89\%PCL-11\%ACPCL copolymer was chosen as the tubular construct because it possesses exceptional shape memory properties $\left(R_{\mathrm{f}}\right.$ and $\left.R_{\mathrm{r}}>99 \%\right)$, a $T_{\mathrm{m}}$ close to body temperature $\left(37.9^{\circ} \mathrm{C}\right)$, and the highest EC biocompatibility after $91 \mathrm{~h}(103.0 \%)$. A murine model of hindlimb ischemia was chosen because it is a well-established method for inducing ischemic environments commonly encountered by medical devices utilized in vascular applications such as stents and grafts [65-67]. After two weeks, H\&E staining of the harvested tubular SMP constructs reveals successful cellularization without inflammatory exacerbation as evidenced by the absence of foreign body giant cell formation or observable fibrotic tissue formation (Fig. 7). While further long-term in vivo studies are required for use in a particular application, this preliminary result of mild host immune responses and good biocompatibility suggests that SMP constructs are a promising material to address vascular injury in an ischemic environment.

\section{Conclusions}

In conclusion, $x \%$ PCL- $y \%$ ACPCL crosslinked networks are the first SMPs with crosslinked pendant allyl groups, providing a robust, facile pendent crosslinking method to control material properties for biomedical applications. As allyl composition controls both the crystallinity and spacing of netpoints, subtle changes in molar composition result in drastic alterations in thermomechanical properties. Molecular weight and gel content can also be adjusted in this copolymerization format to fine-tune material properties. Such a convenient approach can be readily adapted to other promising polymer systems, and bioactive compounds can be incorporated into the crosslinked SMP networks to provide additional functionality. The SMPs possess excellent shape memory properties ( $R_{\mathrm{f}}$ and $R_{\mathrm{r}}>98 \%$ for most test films) and a suitable range of melting temperatures $\left(43.4-29.7^{\circ} \mathrm{C}\right.$ ) for physiological applications. Films are compliant and ductile with appropriate elastic moduli (70.8-2.48 MPa) for vascular applications. Moreover, these SMPs are compatible with vascular endothelial cells (ECs), as indicated in vitro by high levels of cell viability ( $\geqslant 85 \%$ after $91 \mathrm{~h}$ relative to TCPS) and healthy cell morphologies. A copolymer construct exhibited successful cellularization without inflammatory exacerbation in a murine model of hindlimb ischemia, indicating the promise of vascular compatibility in vivo.

Switch-like shape responses near body temperature, tunable mechanical properties, hydrolytic degradability and vascular compatibility of $x \%$ PCL- $y \%$ ACPCL copolymers indicate a promising material for constructing stents, vascular grafts, and other medical devices. However, further studies are required before any of this translational potential can be realized. While preliminary short-term results suggest vascular compatibility, a long-term examination of in vivo biocompatibility and biodegradability with relevant controls and endpoints is required to adequately ensure the absence of strong host inflammatory reactions to $x \%$ PCL- $y \%$ ACPCL copolymers and its degradation products [36]. Hemocompatibility tests to assess thrombotic risks from these materials are mandatory. Scalable fabrication techniques, packaging and storage requirements, and other additional testing requirements specific to the type of device desired would also need to be determined. For example, stents comprised of an $x \%$ PCL- $y \%$ ACPCL copolymer would also require a rational determination of device surface area and surface roughness and evaluation of radial expansion forces, pressure test ratings, fatigue, hysteresis, and radio opacity $[16,32,17,82]$.

Another critical element that needs to be addressed for the ultimate utilization of these $x \%$ PCL- $y \%$ ACPCL copolymers in minimally-invasive applications is the demonstration of their deployment and recovery from minimally-invasive devices [83]. Depending on whether immediate or delayed onset of actuation is desired in the minimally-invasive surgical procedure and the mechanical requirements of the particular application, the physicochemical properties (i.e. molar composition, molecular weight, and gel content) of the material can be adjusted such that the implant recovers its original device-specific shape at body temperature or slightly above it via very mild resistive heating. In the latter scenario, safe and consistent supplemental heating requirements and methods would need to be determined that achieve sufficient, reliable shape recovery. Direct heating or more nuanced localized 
heating techniques involving ultrasound [84], magnetic fields $[3,85]$, electrical currents $[4,86]$, or photothermal activation [8791] have all been utilized toward this end. However, these latter three modes may require incorporation of magnetic nanoparticles (e.g. iron oxide), conductive materials (e.g. carbon nanotubes), or light absorbers (e.g. graphene, gold nanorods, metal complexes, carbon nanotubes, or organic dyes) [9] to produce enough heat for full shape recovery.

The readily-tunable, combinatorial nature of this SMP library provides a unique platform to elucidate unknown structure-function relationships to advance biomaterial and SMP fabrication techniques and optimize material properties for a particular application. A rational optimization approach would involve (1) first defining the ideal outcome from administering the device (e.g. maximized radial expansion and endothelialization with minimal platelet adhesion to achieve long-term patency with no thrombotic events from stent implantation), (2) hypothesizing the ideal material characteristics to achieve these functional goals (e.g. stiffer material with enhanced surface roughness), and (3) carrying out all tests required for the specific application. (4) Examination of other studies, modeling approaches such as finite element analysis depicting the characteristic equations that determine the functional or material properties, and covariance or principle component analysis could aid in determining the physicochemical properties (e.g. molar composition, molecular weight, crosslinking density, surface roughness, surface area) that generate the desired material or functional properties. If necessary or desired, the existing $x \% \mathrm{PCL}-y \% \mathrm{ACPCL}$ copolymer library can be iteratively expanded upon to more precisely elucidate these relationships. Future studies can examine the adaptability of this unique material design involving pendant allyl crosslinkers to other polymer systems, as well as the effects of incorporating bioactive molecules. This may be desired to achieve material and functional properties that cannot be achieved within this $x \%$ PCL- $y \% A C P C L$ copolymer library for other biomedical, aeronautical, or industrial applications.

\section{Acknowledgments}

This study was supported by NSF CAREER CBET 1056046 and NSF DMR 1006558. Confocal images were performed in part through the use of the VUMC Cell Imaging Shared Resource (supported by NIH Grants CA68485, DK20593, DK58404, HD15052, DK59637 and EY08126). ${ }^{1} \mathrm{H}$ NMR was conducted in the Small Molecule NMR Facility Core, and the Translational Pathology Shared Resources Core assisted in the preparation and staining of histological specimens. The authors would also like to acknowledge Mr. Joshua M. Stewart, James Taylor, and Krystian A. Kozek for their assistance in chemical synthesis.

\section{Appendix A. Figures with essential color discrimination}

Certain figures in this article, particularly Figs. 1-7, are difficult to interpret in black and white. The full color images can be found in the on-line version, at http://dx.doi.org/10.1016/j.actbio.2015. 06.004.

\section{Appendix B. Supplementary data}

Supplementary data associated with this article can be found, in the online version, at http://dx.doi.org/10.1016/j.actbio.2015.06.004.

\section{References}

[1] A. Lendlein, S. Kelch, Shape-memory polymers, Angew. Chem. Int. Ed. 41 (2002) 2034-2057.
[2] A. Lendlein, H. Jiang, O. Jünger, R. Langer, Light-induced shape-memory polymers, Nature 434 (2005) 879-882.

[3] A.M. Schmidt, Electromagnetic activation of shape memory polymer networks containing magnetic nanoparticles, Macromol. Rapid Commun. 27 (2006) $1168-1172$.

[4] N.G. Sahoo, Y.C. Jung, J.W. Cho, Electroactive shape memory effect of polyurethane composites filled with carbon nanotubes and conducting polymer, Mater. Manuf. Processes 22 (2007) 419-423.

[5] J. Mendez, P.K. Annamalai, S.J. Eichhorn, R. Rusli, S.J. Rowan, E.J. Foster, et al. Bioinspired mechanically adaptive polymer nanocomposites with wateractivated shape-memory effect, Macromolecules 44 (2011) 6827-6835.

[6] X.J. Han, Z.O. Dong, M.M. Fan, Y. Liu, Y.F. Wang, OJ. Yuan, et al., pH-induced shape-memory polymers, Macromol. Rapid Commun. 33 (2012) 1055-1060.

[7] L. Sun, W.M. Huang, Z. Ding, Y. Zhao, C.C. Wang, H. Purnawali, et al., Stimulusresponsive shape memory materials: a review, Mater. Des. 33 (2012) 577-640.

[8] J. Hu, Y. Zhu, H. Huang, J. Lu, Recent advances in shape-memory polymers: structure, mechanism, functionality, modeling and applications, Prog. Polym. Sci. 37 (2012) 1720-1763.

[9] G.J. Berg, M.K. McBride, C. Wang, C.N. Bowman, New directions in the chemistry of shape memory polymers, Polymer 55 (2014) 5849-5872.

[10] K.K. Julich-Gruner, C. Löwenberg, A.T. Neffe, M. Behl, A. Lendlein, Recent trends in the chemistry of shape-memory polymers, Macromol. Chem. Phys. 214 (2013) 527-536

[11] C. Liu, H. Qin, P. Mather, Review of progress in shape-memory polymers, J. Mater. Chem. 17 (2007) 1543-1558.

[12] T. Pretsch, Review on the functional determinants and durability of shape memory polymers, Polymers 2 (2010) 120-158.

[13] W. Small, P. Singhal, T.S. Wilson, D.J. Maitland, Biomedical applications of thermally activated shape memory polymers, J. Mater. Chem. 20 (2010) 33563366.

[14] M.C. Serrano, G.A. Ameer, Recent insights into the biomedical applications of shape-memory polymers, Macromol. Biosci. 12 (2012) 1156-1171.

[15] A. Lendlein, M. Behl, B. Hiebl, C. Wischke, Shape-memory polymers as a technology platform for biomedical applications, Expert Rev. Med. Devices 7 (2010) 357-379.

[16] L. Xue, S. Dai, Z. Li, Biodegradable shape-memory block co-polymers for fast self-expandable stents, Biomaterials 31 (2010) 8132-8140.

[17] C.M. Yakacki, R. Shandas, C. Lanning, B. Rech, A. Eckstein, K. Gall Unconstrained recovery characterization of shape-memory polymer networks for cardiovascular applications, Biomaterials 28 (2007) 2255-2263.

[18] J. Ortega, D. Maitland, T. Wilson, W. Tsai, Ö. Savaş, D. Saloner, Vascular dynamics of a shape memory polymer foam aneurysm treatment technique, Ann. Biomed. Eng. 35 (2007) 1870-1884.

[19] D.J. Maitland, W. Small, J.M. Ortega, P.R. Buckley, J. Rodriguez, J. Hartman, et al, Prototype laser-activated shape memory polymer foam device for embolic treatment of aneurysms, J. Biomed. Opt. 12 (2007). 030504.

[20] W. Small, P.R. Buckley, T.S. Wilson, W.J. Benett, J. Hartman, D. Saloner, et al., Shape memory polymer stent with expandable foam: a new concept for endovascular embolization of fusiform aneurysms, IEEE Trans. Biomed. Eng. 54 (2007) 1157-1160.

[21] J.T. McGinn, S. Usman, H. Lapierre, V.R. Pothula, T.G. Mesana, M. Ruel, Minimally invasive coronary artery bypass grafting: dual-center experience in 450 consecutive patients, Circulation 120 (2009) S78-S84.

[22] W. Small IV, T. Wilson, W. Benett, J. Loge, D. Maitland, Laser-activated shape memory polymer intravascular thrombectomy device, Opt. Express 13 (2005) 8204-8213.

[23] D.J. Maitland, M.F. Metzger, D. Schumann, A. Lee, T.S. Wilson, Photothermal properties of shape memory polymer micro-actuators for treating stroke, Lasers Surg. Med. 30 (2002) 1-11.

[24] M.F. Metzger, T.S. Wilson, D. Schumann, D.L. Matthews, D.J. Maitland, Mechanical properties of mechanical actuator for treating ischemic stroke, Biomed. Microdevices 4 (2002) 89-96.

[25] A. Rachev, L. Felden, D.N. Ku, Design and fabrication of a mechanically matched vascular graft, J. Biomech. Eng. 133 (2011) 091004

[26] W. Trubel, H. Schima, A. Moritz, F. Raderer, A. Windisch, R. Ullrich, et al., Compliance mismatch and formation of distal anastomotic intimal hyperplasia in externally stiffened and lumen-adapted venous grafts, Eur. J. Vasc. Endovasc. Surg. 10 (1995) 415-423.

[27] W.M. Abbott, J. Megerman, J.E. Hasson, G. L'Italien, D.F. Warnock, Effect of compliance mismatch on vascular graft patency, J. Vasc. Surg. 5 (1987) 376382.

[28] D.L. Safranski, K.E. Smith, K. Gall, Mechanical requirements of shape-memory polymers in biomedical devices, Polym. Rev. 53 (2013) 76-91.

[29] S. Paterson-Brown, S. Cheslyn-Curtis, J. Biglin, J. Dye, C.S. Easmon, H.A. Dudley, Suture materials in contaminated wounds: a detailed comparison of a new suture with those currently in use, Br. J. Surg. 74 (1987) 734-735.

[30] T. Bunt, J. Haynes, Synthetic vascular graft infection. The continuing headache Am. Surg. 50 (1984) 43.

[31] T. Bunt, Vascular graft infections: an update, Cardiovasc. Surg. 9 (2001) 225 233

[32] L. Xue, S. Dai, Z. Li, Synthesis and characterization of elastic star shapememory polymers as self-expandable drug-eluting stents, J. Mater. Chem. 22 (2012) 7403-7411. 
[33] M. Ebara, K. Uto, N. Idota, J.M. Hoffman, T. Aoyagi, Shape-memory surface with dynamically tunable nano-geometry activated by body heat, Adv. Mater. 24 (2012) 273-278.

[34] C.C. Shih, S.J. Lin, Y.L. Chen, Y.Y. Su, S.T. Lai, G.J. Wu, et al., The cytotoxicity of corrosion products of nitinol stent wire on cultured smooth muscle cells, J. Biomed. Mater. Res. 52 (2000) 395-403.

[35] M. Serrano, R. Pagani, M. Vallet-Regı, J. Pena, A. Ramila, I. Izquierdo, et al., In vitro biocompatibility assessment of poly ( $\varepsilon$-caprolactone) films using L929 mouse fibroblasts, Biomaterials 25 (2004) 5603-5611.

[36] T.M. Filion, J. Xu, M.L. Prasad, J. Song, In vivo tissue responses to thermalresponsive shape memory polymer nanocomposites, Biomaterials 32 (2011) 985-991.

[37] D. Ratna, J. Karger-Kocsis, Recent advances in shape memory polymers and composites: a review, J. Mater. Sci. 43 (2008) 254-269.

[38] A. Lendlein, A.M. Schmidt, M. Schroeter, R. Langer, Shape-memory polymer networks from oligo ( $\varepsilon$-caprolactone) dimethacrylates, J. Polym. Sci. A Polym. Chem. 43 (2005) 1369-1381.

[39] I.A. Rousseau, Challenges of shape memory polymers: a review of the progress toward overcoming SMP's limitations, Polym. Eng. Sci. 48 (2008) 2075-2089.

[40] A. Lendlein, R. Langer, Biodegradable, elastic shape-memory polymers for potential biomedical applications, Science 296 (2002) 1673-1676.

[41] A. Garle, S. Kong, U. Ojha, B.M. Budhlall, Thermoresponsive semicrystalline poly ( $\varepsilon$-caprolactone) networks: exploiting cross-linking with cinnamoyl moieties to design polymers with tunable shape memory, ACS Appl. Mater. Interfaces 4 (2012) 645-657.

[42] D.P. Nair, N.B. Cramer, T.F. Scott, C.N. Bowman, R. Shandas, Photopolymerized thiol-ene systems as shape memory polymers, Polymer 51 (2010) 4383-4389.

[43] D.P. Nair, N.B. Cramer, M.K. McBride, J.C. Gaipa, R. Shandas, C.N. Bowman, Enhanced two-stage reactive polymer network forming systems, Polymer 53 (2012) 2429-2434

[44] M. Uygun, M.A. Tasdelen, Y. Yagci, Influence of type of initiation on thiol-ene “click" chemistry, Macromol. Chem. Phys. 211 (2010) 103-110.

[45] D.P. Nair, M. Podgórski, S. Chatani, T. Gong, W. Xi, C.R. Fenoli, et al., The Thiol Michael addition click reaction: a powerful and widely used tool in materials chemistry, Chem. Mater. 26 (2013) 724-744.

[46] X. Xu, K.A. Davis, P. Yang, X. Gu, J.H. Henderson, P.T. Mather, Shape memory RGD-containing networks: synthesis, characterization, and application in cell culture, Macromol. Symp. 309-310 (2011) 162-172.

[47] X. Wang, T.C. Boire, C. Bronikowski, A.L. Zachman, S.W. Crowder, H.-J. Sung, Decoupling polymer properties to elucidate mechanisms governing cell behavior, Tissue Eng. B Rev. 18 (2012) 396-404

[48] M.A. Woodruff, D.W. Hutmacher, The return of a forgotten polymerpolycaprolactone in the 21st century, Prog. Polym. Sci. 35 (2010) 1217-1256.

[49] H. Jeong, B. Kim, Y. Choi, Synthesis and properties of thermotropic liquid crystalline polyurethane elastomers, Polymer 41 (2000) 1849-1855.

[50] M. Bothe, K.Y. Mya, E.M.J. Lin, C.C. Yeo, X. Lu, C. He, et al., Triple-shape properties of star-shaped POSS-polycaprolactone polyurethane networks, Soft Matter 8 (2012) 965-972.

[51] H. Luo, Y. Liu, Z. Yu, S. Zhang, B. Li, Novel biodegradable shape memory material based on partial inclusion complex formation between $\alpha-$ cyclodextrin and poly( $\varepsilon$-caprolactone), Biomacromolecules 9 (2008) 2573 2577.

[52] M. Messori, M. Degli Esposti, K. Paderni, S. Pandini, S. Passera, T. Riccò, et al., Chemical and thermomechanical tailoring of the shape memory effect in poly( $\varepsilon$-caprolactone)-based systems, J. Mater. Sci. 48 (2013) 424-440.

[53] K.Y. Mya, H.B. Gose, T. Pretsch, M. Bothe, C. He, Star-shaped POSSpolycaprolactone polyurethanes and their shape memory performance, J. Mater. Chem. 21 (2011) 4827-4836.

[54] S. Neuss, I. Blomenkamp, R. Stainforth, D. Boltersdorf, M. Jansen, N. Butz, et al., The use of a shape-memory poly( $\varepsilon$-caprolactone)dimethacrylate network as a tissue engineering scaffold, Biomaterials 30 (2009) 1697-1705.

[55] G. Mani, M.D. Feldman, D. Patel, C. Agrawal, Coronary stents: a materials perspective, Biomaterials 28 (2007) 1689-1710.

[56] B. Parrish, J.K. Quansah, T. Emrick, Functional polyesters prepared by polymerization of $\alpha$-allyl (valerolactone) and its copolymerization with $\varepsilon$ caprolactone and $\delta$-valerolactone, J. Polym. Sci. A Polym. Chem. 40 (2002) 1983-1990.

[57] A. Mahmud, X.-B. Xiong, A. Lavasanifar, Novel self-associating poly (ethylene oxide)-b lock-poly ( $\varepsilon$-caprolactone) block copolymers with functional side groups on the polyester block for drug delivery, Macromolecules 39 (2006) 9419-9428.

[58] G.A. Molander, C.R. Harris, Sequenced reactions with samarium (II) iodide. tandem intramolecular nucleophilic acyl substitution/intramolecular Barbier cyclizations, J. Am. Chem. Soc. 117 (1995) 3705-3716.

[59] V. Darcos, S. Antoniacomi, C. Paniagua, J. Coudane, Cationic polyesters bearing pendent amino groups prepared by thiol-ene chemistry, Polym. Chem. 3 (2012) 362-368.

[60] C.G. Pitt, F. Chasalow, Y. Hibionada, D. Klimas, A. Schindler, Aliphatic polyesters. I. The degradation of poly ( $\epsilon$-caprolactone) in vivo, J. Appl. Polym. Sci. 26 (1981) 3779-3787.

[61] B. Guo, Y. Chen, Y. Lei, L. Zhang, W.Y. Zhou, A.B.M. Rabie, et al., Biobased poly (propylene sebacate) as shape memory polymer with tunable switching temperature for potential biomedical applications, Biomacromolecules 12 (2011) 1312-1321.
[62] T. Defize, R. Riva, J.-M. Raquez, P. Dubois, C. Jérôme, M. Alexandre, Thermoreversibly crosslinked poly( $\varepsilon$-caprolactone) as recyclable shapememory polymer network, Macromol. Rapid Commun. 32 (2011) 1264-1269.

[63] W. Wagermaier, K. Kratz, M. Heuchel, A. Lendlein, Characterization methods for shape-memory polymers, in: A. Lendlein (Ed.), Shape-Memory Polymers, Springer Berlin Heidelberg, 2010, pp. 97-145.

[64] M.V. Lancaster, R.D. Fields. Microbiocides and conversion of resazurin to resorfurin. Google Patents, 1996.

[65] H. Niiyama, N.F. Huang, M.D. Rollins, J.P. Cooke, Murine model of hindlimb ischemia, J. Vis. Exp. 23 (2009) e1035.

[66] T. Couffinhal, M. Silver, L.P. Zheng, M. Kearney, B. Witzenbichler, J.M. Isner, Mouse model of angiogenesis, Am. J. Pathol. 152 (1998) 1667-1679.

[67] A.L. Zachman, X. Wang, J.M. Tucker-Schwartz, S.T. Fitzpatrick, S.H. Lee, S.A. Guelcher, et al., Uncoupling angiogenesis and inflammation in peripheral artery disease with therapeutic peptide-loaded microgels, Biomaterials 35 (2014) 9635-9648.

[68] X. Hu, X. Chen, S. Liu, Q. Shi, X. Jing, Novel aliphatic poly (ester-carbonate) with pendant allyl ester groups and its folic acid functionalization, J. Polym. Sci. A Polym. Chem. 46 (2008) 1852-1861.

[69] A.S. Karikari, W.F. Edwards, J.B. Mecham, T.E. Long, Influence of peripheral hydrogen bonding on the mechanical properties of photo-cross-linked starshaped poly (D, L-lactide) networks, Biomacromolecules 6 (2005) 2866-2874.

[70] L. Xue, S. Dai, Z. Li, Synthesis and characterization of three-arm poly ( $\varepsilon$ caprolactone)-based poly (ester-urethanes) with shape-memory effect at body temperature, Macromolecules 42 (2009) 964-972.

[71] G. Zhu, G. Liang, O. Xu, O. Yu, Shape-memory effects of radiation crosslinked poly (€-caprolactone), J. Appl. Polym. Sci. 90 (2003) 1589-1595.

[72] F. Li, W. Zhu, X. Zhang, C. Zhao, M. Xu, Shape memory effect of ethylene-vinyl acetate copolymers, J. Appl. Polym. Sci. 71 (1999) 1063-1070.

[73] A. Karimi, M. Navidbakhsh, A. Shojaei, S. Faghihi, Measurement of the uniaxial mechanical properties of healthy and atherosclerotic human coronary arteries, Mater. Sci. Eng. C 33 (2013) 2550-2554.

[74] S. Ota, Current status of irradiated heat-shrinkable tubing in Japan, Radiat. Phys. Chem. 1981 (18) (1977) 81-87.

[75] G. Kleinheins, W. Starkl, K. Nuffer, Special features of quality assurance measures for radiation-cured, heat-shrink products, 1984

[76] G. Kleinhans, F. Heidenhain, Actively moving polymers, Kunststoffe 76 (1986) 1069-1073.

[77] D.M. Feldkamp, I.A. Rousseau, Effect of the deformation temperature on the shape-memory behavior of epoxy networks, Macromol. Mater. Eng. 295 (2010) 726-734

[78] K. Gall, C.M. Yakacki, Y. Liu, R. Shandas, N. Willett, K.S. Anseth, Thermomechanics of the shape memory effect in polymers for biomedical applications, J. Biomed. Mater. Res. A 73 (2005) 339-348.

[79] A.J. McClung, G.P. Tandon, J.W. Baur, Deformation rate-, hold time-, and cycledependent shape-memory performance of Veriflex-E resin, Mech. Time Depend. Mater. 17 (2013) 39-52.

[80] C.X. Lam, D.W. Hutmacher, J.T. Schantz, M.A. Woodruff, S.H. Teoh, Evaluation of polycaprolactone scaffold degradation for 6 months in vitro and in vivo, J, Biomed. Mater. Res. A 90 (2009) 906-919.

[81] T.K.J. Maciaq, L. Wilkins, M.B. Stemerman, R. Weinstein, Organizational behavior of human umbilical vein endothelial cells, J. Cell Biol. 94 (1982) 511-520.

[82] C.-S. Yang, H.-C. Wu, J.-S. Sun, H.-M. Hsiao, T.-W. Wang, Thermo-induced shape-memory PEG-PCL copolymer as a dual-drug-eluting biodegradable stent, ACS Appl. Mater. Interfaces 5 (2013) 10985-10994.

[83] K. Kratz, U. Voigt, A. Lendlein, Temperature-memory effect of copolyesterurethanes and their application potential in minimally invasive medical technologies, Adv. Funct. Mater. 22 (2012) 3057-3065.

[84] G. Li, G. Fei, H. Xia, J. Han, Y. Zhao, Spatial and temporal control of shape memory polymers and simultaneous drug release using high intensity focused ultrasound, J. Mater. Chem. 22 (2012) 7692-7696.

[85] D. Yang, W. Huang, X. He, M. Xie, Electromagnetic activation of a shape memory copolymer matrix incorporating ferromagnetic nanoparticles, Polym. Int. 61 (2012) 38-42.

[86] G. Fei, C. Tuinea-Bobe, D. Li, G. Li, B. Whiteside, P. Coates, et al., Electroactivated surface micropattern tuning for microinjection molded electrically conductive shape memory polyurethane composites, RSC Adv. 3 (2013) $24132-24139$

[87] K.C. Hribar, R.B. Metter, J.L. Ifkovits, T. Troxler, J.A. Burdick, Light-induced temperature transitions in biodegradable polymer and nanorod composites, Small 5 (2009) 1830-1834.

[88] Y. Liu, J.K. Boyles, J. Genzer, M.D. Dickey, Self-folding of polymer sheets using local light absorption, Soft Matter 8 (2012) 1764-1769.

[89] Y. Liu, M. Miskiewicz, M.J. Escuti, J. Genzer, M.D. Dickey, Three-dimensional folding of pre-strained polymer sheets via absorption of laser light, J. Appl. Phys. 115 (2014) 204911.

[90] H. Zhang, J. Zhang, X. Tong, D. Ma, Y. Zhao, Light polarization-controlled shapememory polymer/gold nanorod composite, Macromol. Rapid Commun. 34 (2013) 1575-1579.

[91] H. Zhang, Y. Zhao, Polymers with dual light-triggered functions of shape memory and healing using gold nanoparticles, ACS Appl. Mater. Interfaces 5 (2013) 13069-13075. 